\title{
The Role of Diffusion Weighted Imaging in suspected cases of ovarian cancer
}

\author{
Rahma Farghaly Ali ${ }^{*^{*}}$, Hana Hamdy Nassef ${ }^{1}$, Ahmed Mohamed Ibrahim², Nivine Abdel Moneim Chalabi ${ }^{1}$ and \\ Asmaa Magdy Mohamed ${ }^{1}$
}

\begin{abstract}
Background: Ovarian cancer is a common gynecological malignancy and often diagnosed late with extensive peritoneal and nodal metastasis. Diffusion-weighted imaging (DWI) provides valuable information about the structural properties of the tissue and has shown great value in cancer imaging. Recently developed postprocessing three-dimensional apparent diffusion coefficient (3D ADC) map has a significant value in variable tumors yet its role in ovarian cancer is not well established. We aim to evaluate the added value of DWI and 3D ADC maps in the diagnosis of ovarian masses, detection of nodal and peritoneal deposits, and so appropriate management planning.

Results: Conventional MRI and DWI were performed to fifty-one patients with complex cystic or solid adnexal lesions depicted by gynecological ultrasonography. Results were compared with surgical and histopathologic findings revealing 23/51 (45\%) had malignant ovarian tumors and 28/51 (55\%) had benign ovarian pathologies. The mean $3 D$ ADC values were $0.977 \pm 0.32,0.934 \pm 0.27$, and $0.956 \pm 0.25 \times 10^{-3} \mathrm{~mm}^{2} / \mathrm{s}$ for ovarian, nodal, and peritoneal malignancy respectively which were significantly lower than the mean $3 D$ ADC values of benign ovarian lesions, non-metastatic lymph nodes and benign peritoneal lesions/fat which were measured $1.516 \pm 0.6,1.208 \pm$ 0.25 , and $1.46 \pm 0.43 \times 10^{-3} \mathrm{~mm}^{2} / \mathrm{s}$ respectively.

Conclusion: Adding DWI and 3D ADC maps to routine MRI improves the sensitivity, specificity, and accuracy for detecting ovarian malignancy, nodal, and peritoneal metastasis. They also provide qualitative data helping in the differentiation of malignant and non-malignant entities.
\end{abstract}

Keywords: Conventional MRI, DWI, 3D ADC map, Ovarian malignancy, Peritoneal carcinomatosis

\section{Background}

Of all gynecological malignancy ovarian cancer represents about $2.5 \%$ and representing about $5 \%$ of female cancer death [1]. Primary ovarian tumors are divided into epithelial-stromal tumors, sex cord-stromal tumors, and germ cell tumors [2].

Malignant epithelial tumors account for $90 \%$ of all ovarian malignancy and include high grade serous ovarian cancer, low grade serous ovarian cancer, endometrioid carcinoma, clear cell carcinoma, and mucinous

\footnotetext{
* Correspondence: rahmafarghaly91@gmail.com

${ }^{1}$ Radiology Department, Faculty of Medicine, Ain Shams University, Cairo, Egypt

Full list of author information is available at the end of the article
}

carcinoma [3]. Up to $65 \%$ of patients with epithelial carcinoma are diagnosed at FIGO stages III and IV with peritoneal and nodal deposits [4].

Secondary ovarian tumors mostly originate from the endometrium, the pancreas, the gastrointestinal tract, and the breast. Most of them are clinically and pathologically mimic the primary tumors [5].

Although staging laparotomy and histopathological examination are the gold standard methods for staging in all women suspected of having ovarian carcinoma, it is necessary to explore less invasive preoperative methods for staging and detection of nodal and peritoneal deposits [6].

The major roles of diagnostic imaging have been to characterize the ovarian mass, determine the extent of

Springer Open

(c) The Author(s). 2020 Open Access This article is licensed under a Creative Commons Attribution 4.0 International License, which permits use, sharing, adaptation, distribution and reproduction in any medium or format, as long as you give appropriate credit to the original author(s) and the source, provide a link to the Creative Commons licence, and indicate if changes were made. The images or other third party material in this article are included in the article's Creative Commons licence, unless indicated otherwise in a credit line to the material. If material is not included in the article's Creative Commons licence and your intended use is not permitted by statutory regulation or exceeds the permitted use, you will need to obtain permission directly from the copyright holder. To view a copy of this licence, visit http://creativecommons.org/licenses/by/4.0/. 
preoperative disease, predict tumor resectability, and evaluate response to chemotherapy [7].

Pelvic and abdominal CT with both oral and intravenous (IV) contrast is the modality of choice in the pre-operative assessment of disease extension as well as predicting the success of surgical cytoreduction [8].

The doses of ionizing radiation to which the population has been exposed are increasingly higher due to its use in medical applications for the diagnosis and treatment of diseases. In 2008, the CT scan in the USA was the diagnostic technique that showed the highest dose deposition in the population [9]. So we are in need to use imaging techniques with low or no radiation hazards.

Ovarian cancer as other malignant tumors is characterized by neovascularization which predicts the metastatic properties of the tumor. Newly developed radiolabeled monoclonal antibodies have been settled for both the diagnosis and treatment of tumors in targeted radiotherapy [10].

MRI has flexibility for imaging anatomy, physiological parameters, and biochemical function, through appropriate choice of pulse sequences [11].

Diffusion MRI measures the diffusivity of endogenous water molecules in a tissue that reflects the mean size of the tissue microstructure that restricts and/or hinders the Brownian random motion of water molecules [12].

DWI allows the construction of 3D ADC maps of water molecules, that are promising markers of internal tumor pores and cellular gaps in which water molecules can migrate [11].

The primary focus of the research was the assessment of DWI for the qualitative evaluation of certain tumors. This focus has gradually shifted toward more quantitative methods of DWI assessment, including a large number of studies on the use of the main quantitative measure of DWI (ADC maps) [13].

Few articles have been reported; the diagnostic application of the DWI and ADC maps in the characterization and staging of ovarian tumors yet most of these studies have used the 2D ADC maps [14, 15].

This study evaluated the usefulness of diagnosis and preoperative staging of ovarian cancer (including characterization of ovarian lesions, detection of nodal, and peritoneal metastasis), using qualitative and quantitative analysis of DWI, and recently developed postprocessing method (3D ADC maps).

\section{Methods}

\section{Patients}

This prospective study was performed from June 2018 till January 2020, and it included fifty-one adult females who had a complex cystic or solid adnexal lesion by transvaginal or trans-abdominal ultrasound examination with a mean age $45 \pm$ 13.9-year-old (range of 16-74). Patients were referred to our radiology department in ElDemerdash Hospital for further assessment of the adnexal lesions.

Non-contrast MRI studies including conventional pelvic-abdominal images and DWI were done for all participants, after written consent was taken, according to the rules of our ethical committee. The results were confirmed by histopathology (Fig. 1).

The proper exclusion criteria were the following:

- Patients with previous adnexal surgical intervention

- Patients who received RTH or CTH or any treatment before MRI examination

- Patient with contraindication to MRI e.g. non-MRI compatible pacemaker

\section{MRI examination}

- Patients were injected with Buscopan intramuscularly $20 \mathrm{~min}$ before the examination to suppress bowel contractions, thereby avoiding DWI misreading of intestinal serosal deposits.

- MRI examination including conventional and DW images was done for all participants using $1.5 \mathrm{~T}$ Philips Achieva MRI unit with body Torso coil. The following conventional images were included:

- Pelvis MRI included

- Axial T1w-TSE (TR/TE, 550/24 ms), slice thickness $5 \mathrm{~mm}$, gap $1 \mathrm{~mm}$, and FOV $36 \mathrm{~cm}$. Matrix $576 \times$ 576.

- Axial T2w-TSE (TR/TE, 7649/115 ms), slice thickness $5 \mathrm{~mm}$, gap $1 \mathrm{~mm}$, and FOV $36 \mathrm{~cm}$. Matrix 560 $\times 560$.

- Sagittal and coronal T2-weighted, slice thickness 8$10 \mathrm{~mm}$, gap $1 \mathrm{~mm}$, and FOV $72-80 \mathrm{~cm}$.

- DW-MRI was acquired in the axial plane by using a single-shot echo-planar imaging sequence with $b$ values 0,200 , and 800 , TR/TE 4274/63, slice thickness $5 \mathrm{~mm}$, gap $1 \mathrm{~mm}$, FOV $36 \mathrm{~cm}$. Matrix $384 \times$ 384.

- Abdomen MRI included

- Axial T2w-TSE (TR/TE, 450/80 ms), slice thickness $6 \mathrm{~mm}$, gap $1 \mathrm{~mm}$, and FOV $36 \mathrm{~cm}$. Matrix $480 \times$ 480.

- DW-3b (TR/TE 3793/65 ms), Slice thickness 6 mm, gap $1 \mathrm{~mm}$, FOV $36 \mathrm{~cm}$. Matrix $288 \times 288$.

- DWI at $b$ value 800 was processed into inverted grayscale DWI using synapse. The SYNAPSE, Product Release Specification, Software Version 4.4, ENG-0034171-A, March 13th, 2015, SYNAPSE is a registered trademark of FUJIFILM Medical Systems, USA. 


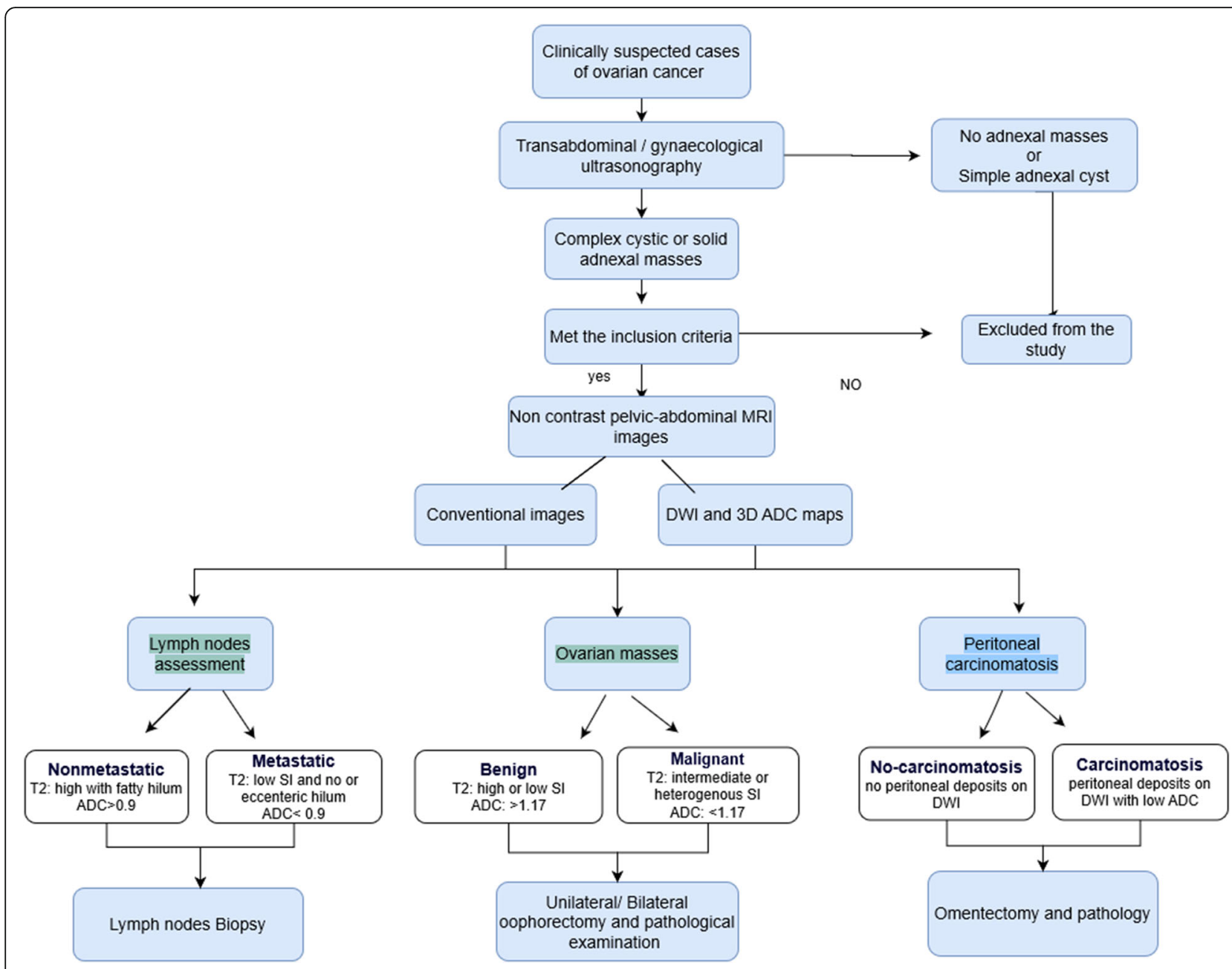

Fig. 1 Flow chart demonstrating the methodology

- 3D apparent diffusion coefficient (ADC) map was generated on the 3D synapse.

- The mean ADC values measured for the solid component of the ovarian lesions, lymph nodes, and peritoneal deposits.

\section{Analysis of data}

- The images were then reviewed by two gynecological radiologists (with 10 and 5 years' experience in female radiology) with specific points to comment on qualitative, and quantitative analysis of ovarian lesions, lymph nodes, and peritoneal carcinomatosis:

- Ovarian masses-unilateral or bilateral, solid or complex cystic (with septations, papillary projection, or soft tissue component), restricted or facilitated diffusion, and 3D ADC value of the solid component.
- Nodal assessment-site, size, restriction pattern compared to the solid component of ovarian masses, and 3D ADC value.

- Peritoneal thickening-presence or absence, size of nodules, anatomical site including omentum, peritoneal surface and serosa, and 3D ADC values.

- The two radiologists viewed the DWI and MRI data via a 3D synapse system without any knowledge of the pathological information. When there was a difference between them, a final decision was made by consensus.

- Forty-five patients underwent a total abdominal hysterectomy, oophorectomy, omentectomy, and lymph nodes biopsy. Six cases underwent unilateral oophorectomy. All results were correlated to the final post-operative histopathological data.

\section{Statistical analysis}

The data analysis was performed using the IBM SPSS statistics (V. 25.0, IBM Corp., USA, 2017-2018). For 
quantitative parametric measurements, the data were expressed as mean $\pm \mathrm{SD}$. A receiver operating characteristic (ROC) curve was performed to assess the diagnostic accuracy of the measured ADC value for diagnosing malignant ovarian and nodal lesions using diagnostic validity tests which included sensitivity and specificity. $P$ value $<0.05$ was considered a statistically significant value. $P$ value $<0.001$ was considered a highly statistically significant value.

\section{Results}

This study included fifty-one female patients, their ages ranged between 16 and 74 years with mean age $45 \pm$ 13.9 years old.

\section{Characterization of ovarian lesions}

From fifty-one cases, twenty-three cases showed malignant histopathology (45\%) (Fig. 2) and twenty-eight cases showed benign histopathology (55\%) (Table 1). Four cases showed bilateral ovarian lesions yet the most suspicious lesion of both ovarian lesions only included in this study to avoid bias.

The conventional MR combined with DW images were accurate in detecting ovarian malignancy yet 8 false-positive cases with solid components, intermediate or heterogeneous T2wi SI and low ADC values were reported, these cases were cases of necrotizing caseating granuloma, tubo-ovarian abscesses, mature cystic teratomas, infarcted ovary, and cystadenofibroma (Table 2).

These combined images showed $100 \%$ sensitivity, 71.4\% specificity, 100\% NPV, 74.2\% PPV, and $84.3 \%$ efficacy. Yet the accuracy of conventional MRI alone without DWI in the characterization of the ovarian lesion was $80 \%$ with $91.3 \%$ sensitivity, $64.29 \%$ specificity, $90 \%$ NPV, and $67.7 \%$ PPV.

In this study, two false-negative cases were reported, which were detected by the combined MRI/DWI yet were missed on conventional MRI alone, the first one was a very small malignant epithelial tumor, and the second one was ovarian surface small deposits secondary to malignant mesothelioma. Both of these malignant lesions were missed by conventional MRI images, yet restricted in the DWI.

Regarding ovarian lesions signal intensity in both DWI and 3D ADC map, 21/23 of malignant pathologies $(91.3 \%)$ were restricted and only $2 / 23$ pathologies $(8.7 \%)$ were facilitated. The facilitated pathologies were metastatic from the colon with complex cystic morphology. Yet 17/28 benign lesions were restricted (60.7\%) and 11/ 28 pathologies $(39.3 \%)$ were facilitated. The restricted benign cases were cases of mature cystic teratomas, tubo-ovarian abscess, fibromas, fibrothecomas, cystadenofibroma, tubo-ovarian abscesses, and infarcted ovary.

The mean value of ADC of the malignant ovarian lesions was statistically significantly lower than that of the benign ovarian lesions $(0.977 \pm 0.3$ and $1.516 \pm 0.6$ respectively) (Table 3).

Based on the area under the ROC curve of 0.756, the cutoff value below which malignancy is expected is less than $1.17 \times 10^{-3} \mathrm{~mm}^{2} / \mathrm{s}$ with $69.9 \%$ sensitivity, and $75 \%$ specificity (Fig. 3).

\section{Detection of nodal deposits}

The histopathological results assessed only in fortyseven patients out of the fifty-one patients, and it revealed metastatic LN in eleven cases, yet the LN was benign in thirty-six cases.

The conventional MR combined with DW images were accurate in detecting metastatic LNs yet 5 falsepositive cases with low $\mathrm{ADC}$ values were reported, three of them were associated with benign ovarian pathologies (necrotizing caseating granuloma and tubo-ovarian abscesses) and two associated with malignant ovarian

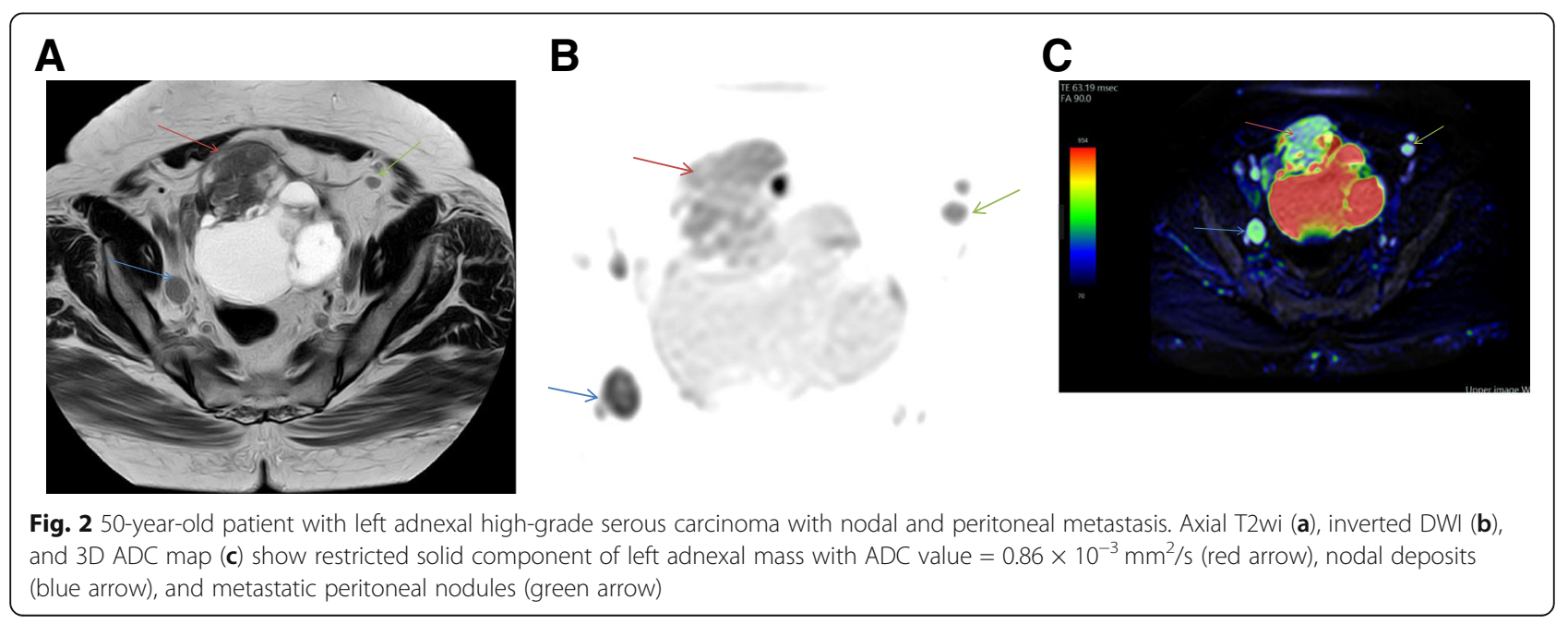


Table 1 Ovarian masses pathological classification

\begin{tabular}{llll}
\hline Ovarian lesions subtypes & & & \\
\hline Malignant & NB (\%) & Benign & NB (\%) \\
\hline *Primary ovarian tumors & $6(11.7)$ & Serous cystadenoma & Mature teratoma \\
High-grad papillary serous & $4(7.8 \%$ & Mucinous cystadenoma & $3(5.9 \%)$ \\
Low-grade papillary serous & $1(1.9 \%)$ & Fibrothecoma & $3(5.9 \%)$ \\
Mucinous adenocarcinoma & $1(1.9 \%)$ & Fibroma & $3(5.9 \%)$ \\
Endometrioid adenocarcinoma & $2(3.9 \%)$ & Endometrioid cystadenoma & $2(3.9 \%)$ \\
Malignant germ cell tumor & $1(1.9 \%)$ & Endometrioidcystadenofibroma & $1(1.9 \%)$ \\
Malignant granulosa cell & $1(1.9 \%)$ & Endometriosis with abscess & $1(1.9 \%)$ \\
Malignant endodermal sinus tumor & & Tubo-ovarian abscess & $2(3.9 \%)$ \\
*Metastatic ovarian tumors & $2(3.9 \%)$ & Necrotizing caseating granuloma & $4(7.8 \%)$ \\
Endometrial cancer & $1(1.9 \%)$ & Infarcted ovary & $1(1.9 \%)$ \\
Uterine leiomyosarcoma & $2(3.9 \%)$ & & $1(1.9 \%)$ \\
Colon adenocarcinoma & $1(1.9 \%)$ & & \\
Gastric carcinoma & $1(1.9 \%)$ & & \\
Malignant mesothelioma & & & \\
\hline
\end{tabular}

pathologies with histopathologically proven free lymph nodes (Table 2).

The combined images showed 100\% sensitivity, $86.1 \%$ specificity, $100 \%$ NPV, $68.8 \%$ PPV, and $89.4 \%$ efficacy in detecting LNs deposits. Yet the accuracy of conventional MRI alone without DWI was $76.6 \%$ with $63.64 \%$ sensitivity, $80.56 \%$ specificity, $87.88 \%$ NPV, and $50 \% \mathrm{PPV}$.

Conventional MRI images showed lower sensitivity than that of combined images in the detection of nodal metastasis as $4 / 11(36.37 \%)$ of metastatic lymph nodes were small and missed by conventional images.

The mean 3D ADC value of malignant nodal deposits was statistically significantly lower than that of the nonmetastatic lymph nodes (measured $0.934 \pm 0.27$ and $1.208 \pm 0.25$ respectively) (Table 3 ).
The lymph node restriction degree compared to that of the solid component of the ovarian masses was statistically significant in differentiating metastatic and nonmetastatic lymph nodes with $p=0.000$ (Table 4). As $45.5 \%$ of metastatic lymph nodes had the same degree of restriction compared to the solid component of ovarian masses and $36.4 \%$ were restricted more than the solid component. This compared to $8.3 \%$ of the nonmetastatic lymph nodes which had the same degree of restriction as to the solid component and $2 \%$ of them were restricted more than the solid component of ovarian masses.

Based on the area under the ROC curve of 0.868 the cutoff value below which malignancy is expected is less than $0.9 \times 10^{-3} \mathrm{~mm}^{2} / \mathrm{s}$ with $63.6 \%$ sensitivity, and $80.6 \%$ specificity (Fig. 3).

Table 2 Conventional MRI combined with DWI in detection of ovarian malignancy, nodal, and peritoneal deposits correlated to histopathology

\begin{tabular}{|c|c|c|c|c|c|}
\hline \multicolumn{2}{|c|}{ Conventional MRI and DWI } & \multicolumn{2}{|c|}{ Histopathology } & \multicolumn{2}{|c|}{ Pearson chi-square } \\
\hline & & \multirow{2}{*}{$\frac{\text { Malignant }}{23(100 \%)}$} & \multirow{2}{*}{$\begin{array}{l}\text { Non-malignant } \\
8(28.6 \%)\end{array}$} & \multirow{2}{*}{$\begin{array}{l}\text { Value } \\
27.028^{\mathrm{a}}\end{array}$} & \multirow{2}{*}{$\frac{P^{*}}{0.000}$} \\
\hline Ovarian Masses & Malignant & & & & \\
\hline & Benign & $0(0 \%)$ & $20(71.4 \%)$ & & \\
\hline & Total & $23(100 \%)$ & $28(100 \%)$ & & \\
\hline \multirow[t]{3}{*}{ Lymph nodes } & Metastatic & $11(100 \%)$ & $5(13.9 \%)$ & $27.825^{\mathrm{a}}$ & 0.000 \\
\hline & Non-metastatic & $0(0 \%)$ & $31(86.1 \%)$ & & \\
\hline & Total & $11(100 \%)$ & $36(100 \%)$ & & \\
\hline \multirow[t]{3}{*}{ Peritoneal deposits } & Carcinomatosis & $18(100 \%)$ & $3(9 \%)$ & $39.7403^{a}$ & 0.000 \\
\hline & No carcinomatosis & $0(0 \%)$ & 30 (90.9\%) & & \\
\hline & Total & $18(100 \%)$ & $33(100 \%)$ & & \\
\hline
\end{tabular}

Chi-square tests $-P$ value $>0.05$, non significant; $P$ value $<0.05$, significant; $P$ value $<0.001$, highly significant athe significance level 
Table 3 Mean 3D ADC values of histopathologically proved malignant and non-malignant ovarian lesions, lymph nodes, and peritoneal deposits

\begin{tabular}{lllll}
\hline & Pathology & $N$ & Mean value & $P^{*}$ \\
\hline Ovarian masses & Benign & 28 & $1.516 \pm 0.6$ & 0.003 \\
& Malignant & 23 & $0.977 \pm 0.3$ & \\
Lymph nodes & Non-malignant & 36 & $1.208 \pm 0.25$ & 0.006 \\
& Malignant & 11 & $0.934 \pm 0.27$ & \\
Peritoneal deposits & No carcinomatosis & 33 & $1.46 \pm 0.43$ & 0.001 \\
& Carcinomatosis & 18 & $0.956 \pm 0.25$ & \\
\hline
\end{tabular}

Wilcoxon rank-sum test-ADC value $\left(\times 10^{-3} \mathrm{~mm}^{2} / \mathrm{s}\right)$

${ }^{*} P$ value $>0.05$, non significant; $P$ value $<0.05$, significant; $P$ value $<0.01$, highly significant

\section{Assessment of peritoneal deposits}

Peritoneal carcinomatosis was histopathologically confirmed in 18 cases (35.3\%) (Fig. 4), other thirty-three cases $(64.7 \%)$ had no carcinomatosis with only three cases showing benign peritoneal thickening on histopathology (Figs. 5 and 6).

The combined conventional MR and DW images were accurate in detecting peritoneal carcinomatosis (Table 2) with 100\% sensitivity, 90.91\% specificity, 100\% NPV, 85.71\% PPV, and $94.12 \%$ efficacy.

Yet the accuracy of conventional MRI alone without DWI in the detection of peritoneal deposits was $90.2 \%$ with $88.89 \%$ sensitivity, $90.91 \%$ specificity, $93.75 \%$ NPV, and $84.21 \%$ PPV.

Three false-positive cases associated with benign ovarian pathologies two of them were diffuse granulomatous and inflammatory thickening in cases of necrotizing caseating granuloma, tubo-ovarian abscess. The third one showed small nodular thickening (peritoneal particulates) which was seen in the case of ovarian infarction.
Two false-negative cases in the form of tiny peritoneal metastatic deposits were missed by conventional MRI alone and detected by DWI.

Peritoneal carcinomatosis deposits were smaller than $10 \mathrm{~mm}$ in two cases (11.1\%) and larger than $10 \mathrm{~mm}$ in five cases (27.8), yet it was confluent in eleven cases (61.1\%). Non-malignant peritoneal thickening was smaller than $10 \mathrm{~mm}$ in one case (3\%) and confluent in two cases (6.1\%) (Table 5).

The mean 3D ADC value of peritoneal carcinomatosis was statistically significantly lower than that of noncarcinomatosis (including the ADC value of peritoneal fat in cases where there were no peritoneal thickening and the ADC value of benign peritoneal thickening) measuring $0.956 \pm 0.25$ and $1.46 \pm 0.43$ respectively (Table 3).

\section{Discussion}

Ovarian cancer is often diagnosed late with extensive peritoneal metastases [FIGO stages IIIc and IV], decreasing the patient's survival rate to $10 \%$ in FIGO stage IV and $20-40 \%$ in FIGO stage IIIc disease [16] (Fig. 3).

Cancer staging is a fundamental principle and one of the first and most important steps used to predict the patient outcomes as well as to plan the most appropriate treatment [17].

In this study, DWI combined with conventional MR images were used for staging of ovarian cancer aiming that these non-contrast MRI images may become the exam of choice in patients with absolute or relative contraindications to contrast media, e.g., pregnant females (this study included two pregnant cases).

\section{A}

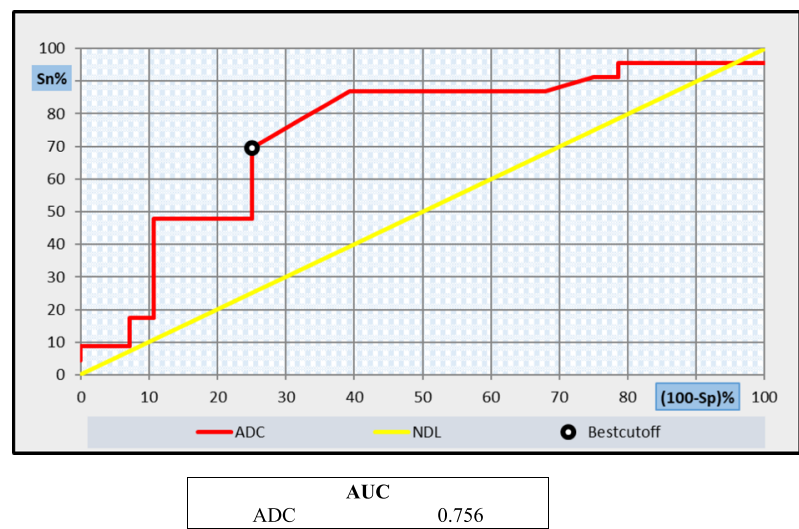

B

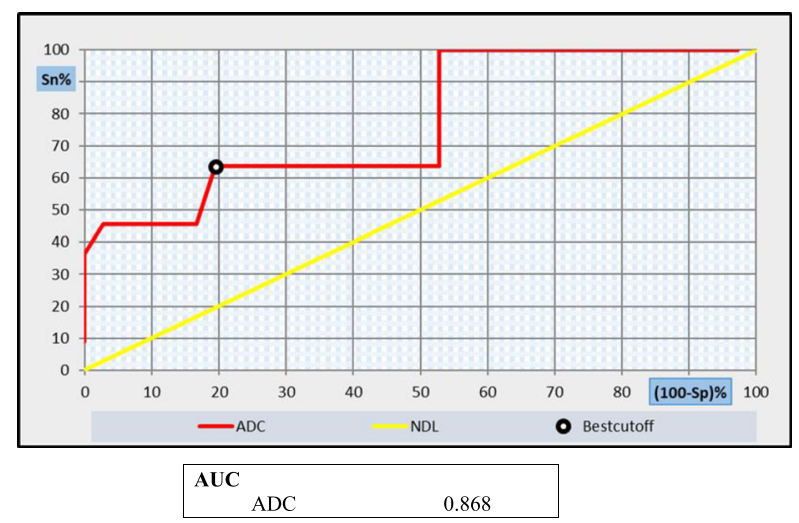

Fig. 3 a ROC curves showing the diagnostic performance of 3D ADC for discriminating patients with malignant ovarian masses from that with benign histology $(A \cup C=0.756)$. $\mathbf{b}$ ROC curves showing the diagnostic performance of $3 D$ ADC for discriminating patients with malignant ovarian masses from that with benign histology $(A \cup C=0.868)$ 
Table 4 Degree of lymph nodes restriction compared to the solid component of ovarian masses

\begin{tabular}{llll}
\hline & & Histopathogy & \\
\cline { 3 - 4 } Nodal/ solid component restriction & & Benign & Malignant \\
& < Solid component & $31(86.1 \%)$ & $3(18.2 \%)$ \\
& $=$ Solid component & $3(8.3 \%)$ & $4(45.5 \%)$ \\
Pearson chi-square & $>$ Solid component & $2(5.6 \%)$ & $4(36.4 \%)$ \\
\hline
\end{tabular}

\section{Chi-square test}

${ }^{*} P$ value $>0.05$, non significant; $P$ value $<0.05$, significant; $P$ value $<0.01$ : Highly significant

To our knowledge, this was the first study that used a 3D ADC map in preoperative staging of ovarian cancer. This study included quantitative and qualitative analysis of ovarian masses, lymphatic metastasis, and peritoneal deposits. Yet other studies used 2D ADC maps in the staging of ovarian malignancy.

In this study, combined DW and conventional MRI images showed a high sensitivity (100\%) for the detection of ovarian pathology yet low specificity (71.4\%). This low specificity could be explained by the presence of eight false-positive cases (eight benign adnexal masses that mimicked malignancy). All these cases showed solid adnexal lesions components displayed intermediate or heterogeneous T2wi SI and low ADC values. These cases included necrotizing caseating granuloma, tubo-ovarian abscesses, mature cystic teratomas, infarcted ovary, and cystadenofibroma with mean 3D ADC values of $1.3 \times 10^{-3} \mathrm{~mm}^{2} / \mathrm{s}, 0.63 \times$ $10^{-3} \mathrm{~mm}^{2} / \mathrm{s}, \quad 0.9 \times 10^{-3} \mathrm{~mm}^{2} / \mathrm{s}, \quad 0.53 \times 10^{-3} \mathrm{~mm}^{2} / \mathrm{s}$, and $1.2 \times 10^{-3} \mathrm{~mm}^{2} / \mathrm{s}$ respectively. Few cases of them were also associated with benign peritoneal thickening and enlarged lymph nodes with low 3D ADC values as in cases of necrotizing caseating granuloma and case of tubo-ovarian abscess.

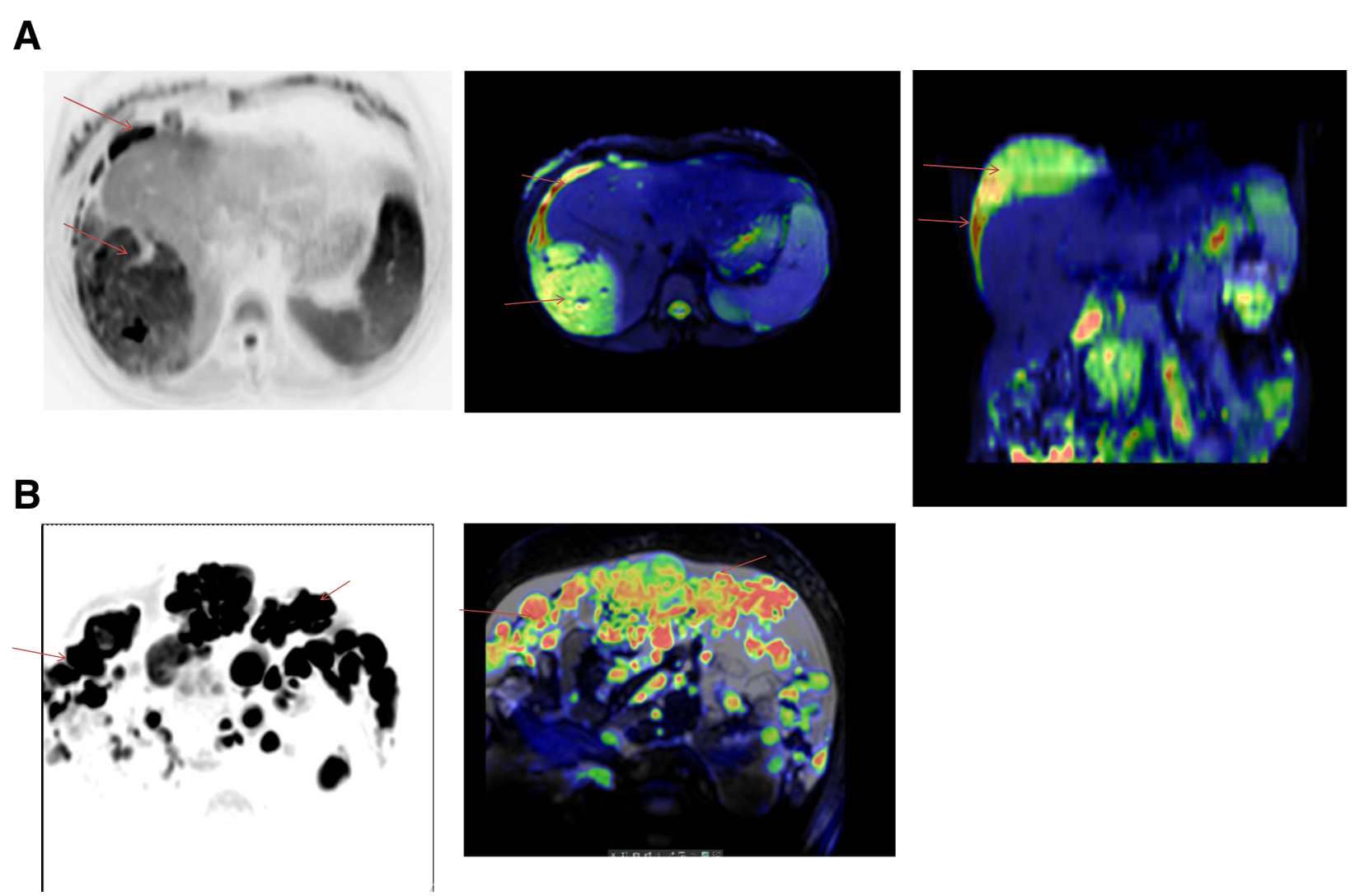

Fig. 4 a Inverted DWI and 3D ADC map showing hepatic surface deposits in case of malignant endodermal sinus tumor (a and b). b Diffuse peritoneal deposits in a case of metastatic leiomyosarcoma as demonstrated by red arrows in inverted DWI and 3D ADC map (c and $\mathbf{d}$ ) 

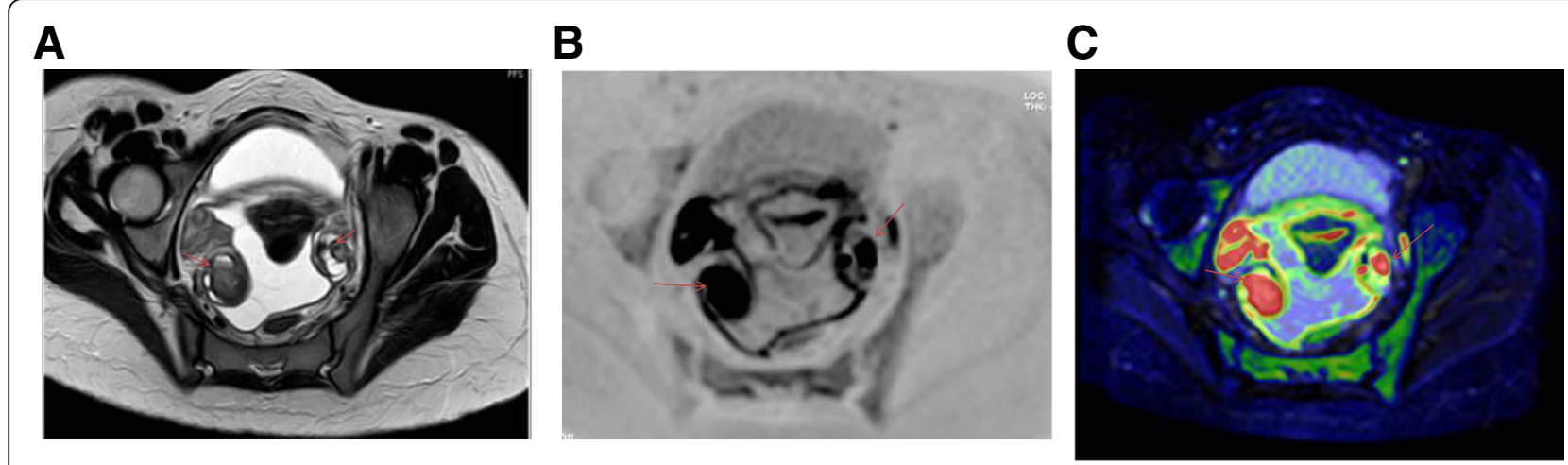

\section{D}

\section{$\mathbf{E}$}
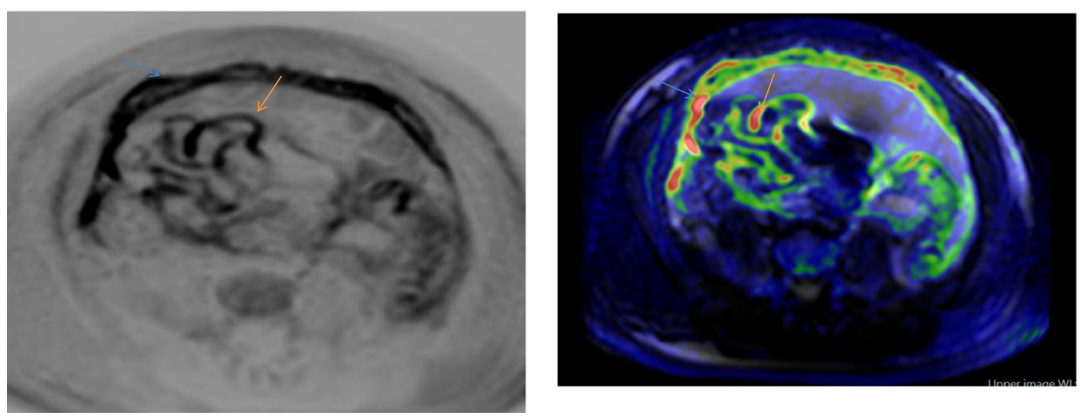

Fig. 5 23-year-old female with bilateral adnexal necrotizing caseating granuloma (b) associated with peritoneal and hepatic involvement. Bilateral complex adnexal cystic lesions are seen in axial T2WI of the pelvis (a). Solid components showing restricted diffusion (red arrows) in both inverted DWI and 3D ADC maps (b and $\mathbf{c}$ ). Inverted DWI and 3D ADC map of the pelvis ( $\mathbf{d}$ and $\mathbf{e}$ ) showing diffuse peritoneal surface (blue arrows) and bowel serosal thickening (orange arrows)

In this study, the mean $3 \mathrm{D} \mathrm{ADC}$ values for benign ovarian lesions were $1.516 \pm 0.6 \times 10^{-3} \mathrm{~mm}^{2} / \mathrm{s}$ and for malignant lesions were $0.977 \pm 0.3 \times 10^{-3} \mathrm{~mm}^{2} / \mathrm{s}$ and the cutoff value below which malignancy is expected is less than $1.17 \times 10^{-3} \mathrm{~mm}^{2} / \mathrm{s}$ with $69.9 \%$ sensitivity, $75 \%$ specificity, 75\% NPV, and 69.6\% PPV.
Takeuchi et al. [18], in their study which included 49 ovarian tumors, 39 of them were malignant/borderline malignant and 10 were benign tumors, found that the mean $2 \mathrm{D}$ ADC value for malignant tumors was significantly lower than that in benign tumors (measured $1.03 \pm 0.19$ and $1.38 \pm 0.30$ respectively). They also

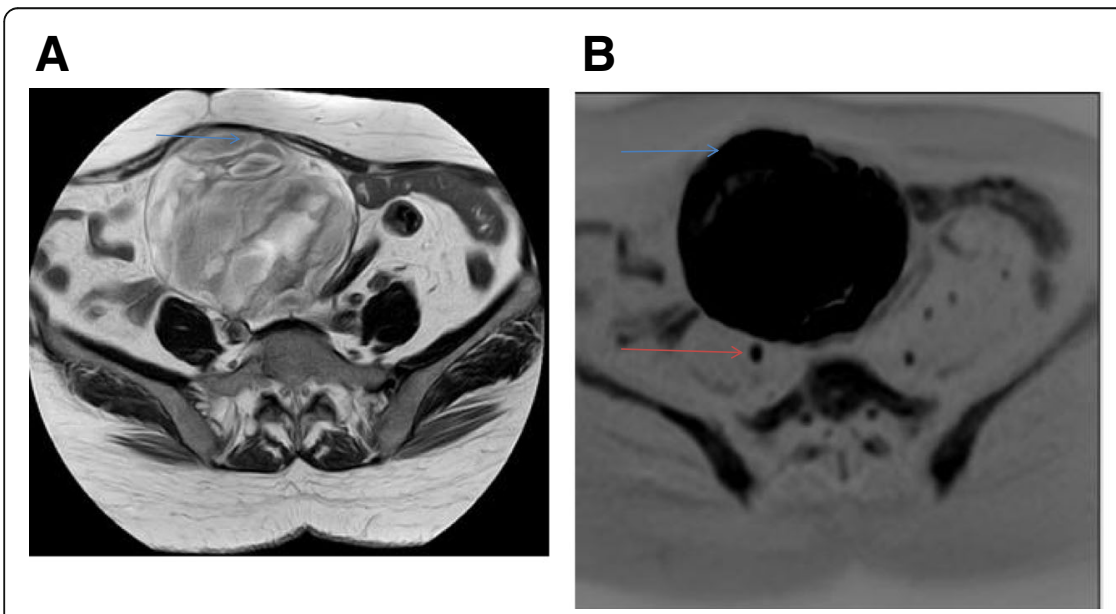

C

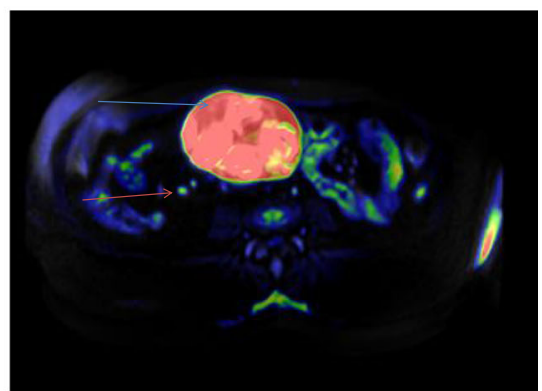

Fig. 6 58-year-old patient with right ovarian infarction and peritoneal particulates. A right complex adnexal lesion with heterogeneous SI in T2wi as seen in figure $\mathbf{a}$. Lesion is truly restricted (blue arrows) with ADC value $=0.53 \times 10^{-3} \mathrm{~mm}^{2} / \mathrm{s}$ as seen in inverted DWI and 3D ADC map (b and c). Small peritoneal lesions also noted (green arrow) 
Table 5 The size of peritoneal thickening/ deposits correlated to histopathology

\begin{tabular}{|c|c|c|c|c|}
\hline & & \multicolumn{2}{|l|}{ Histopathology } & \multirow[b]{2}{*}{ Total } \\
\hline & & No carcinomatosis & Carcinomatosis & \\
\hline \multirow[t]{4}{*}{ Size of peritoneal nodules by MRI } & No nodules & 30 (90.9\%) & $0(0 \%)$ & $30(58.8 \%)$ \\
\hline & nodules $<10 \mathrm{~mm}$ & $1(3 \%)$ & $2(11.1 \%)$ & $1(2 \%)$ \\
\hline & nodules $>10 \mathrm{~mm}$ & $0(0 \%)$ & $5(27.8 \%)$ & $5(9.8 \%)$ \\
\hline & Confluent & $2(6.1 \%)$ & $11(61.1 \%)$ & $15(29.4 \%)$ \\
\hline Total & & $33(100 \%)$ & $18(100 \%)$ & $51(100 \%)$ \\
\hline
\end{tabular}

found the cutoff ADC value of 1.15 malignant lesions had $74 \%$ sensitivity, $80 \%$ specificity, $94 \%$ PPV, and $44 \%$ NPV. The mean ADC value for malignancy was higher than that of this study as this study included malignant ovarian lesions with low ADC values as leiomyosarcoma, and uterine adenocarcinoma with metastatic deposits to ovaries with $\mathrm{ADC}$ values 0.4 , and 0.6 respectively such cases not included in their study.

Li et al. [19], in their study which included 127 patients with 131 lesions, 46 of them were benign and 81 were malignant, found that the $2 \mathrm{D}$ mean $\mathrm{ADC}$ value for benign lesions was $1.69 \times 10^{-3} \mathrm{~mm}^{2} / \mathrm{s} \pm 0.25 \mathrm{SD}$, and $1.03 \times 10^{-3} \pm 0.22 \mathrm{SD} \mathrm{mm} / \mathrm{s}$ for malignant lesions. The cut off value was $1.25 \times 10^{-3} \mathrm{~mm}^{2} / \mathrm{s}$ showed $90.1 \%$ sensitivity and $89.9 \%$ specificity. A lower mean ADC value of benign ovarian masses in this study may attribute to the presence of non-malignant ovarian lesions with low ADC value as tubo-ovarian abscess, infarcted ovary, and necrotizing caseating granuloma, such cases not included in their study as their study only included ovarian lesions originated from surface epithelium.

This is in contrary to the results of El Ameen et al. [20] who had a lower cut off value, and mean ADC value for malignancy $\left(1 \times 10^{-3} \mathrm{~mm}^{2} / \mathrm{s}\right.$, and $0.8 \times 10^{-3} \mathrm{~mm}^{2} / \mathrm{s} \pm$ $0.1 \mathrm{SD}$ respectively). This may attribute to the presence of metastatic cystic tumors from colon included in this study with high ADC values of $1.7 \times 10^{-3} \mathrm{~mm}^{2} / \mathrm{s}$ and 1.9 $\times 10^{-3} \mathrm{~mm}^{2} / \mathrm{s}$. These cases of metastatic adnexal tumors from the colon presented with complex cystic ovarian lesions and by MRI colonic masse were detected with multiple air-fluid levels in one of them. Yet they agreed with this study regarding the sensitivity, specificity, NPV, PPV, and accuracy of conventional MRI without DWI in the characterization of ovarian lesions $(92 \%, 61.11 \%$, $84.6 \%, 76.7 \%$, and $79.1 \%$ ).

Previous studies have suggested that quantitative $2 \mathrm{D}$ ADC analysis may be useful for staging of ovarian cancers and predicting responses to chemotherapy [21-23].

To our knowledge, few studies exploring relationships between ADC values of lymph nodes and lymphatic metastasis were done, one of them performed by Wang et al. [24], including 49 patients with 29 negative cases $(59.2 \%)$ and 20 positives (40.8\%). They agreed with us regarding the statistical significance of $A D C$ values in the detection of metastatic nodal deposits with $p=$ 0.000 . Yet their study showed a higher cut off value $\left(1.003 \times 10^{-3} \mathrm{~mm}^{2} / \mathrm{s}\right)$ with higher specificity (93.1\%). Such lower specificity in this study can be attributed to the presence of acute lymphadenitis in cases of necrotizing caseating granuloma and tubo-ovarian abscess showed low ADC values and reported as malignant lymph nodes.

Other studies also concluded the accuracy of DWI in the characterization of ovarian masses and detection of nodal deposits $[8,19,21]$.

In this study, the conventional MR combined with DW images were accurate in detecting peritoneal carcinomatosis with $100 \%$ sensitivity, $90.91 \%$ specificity, $100 \%$ NPV, $85.71 \%$ PPV, and $94.12 \%$ efficacy. The size of peritoneal carcinomatosis was smaller than $1 \mathrm{~cm}$ in 11.1 $\%$ and larger than $1 \mathrm{~cm}$ in $27.8 \%$ and $61.1 \%$ showed confluent disease.

Michielsen et al. [14] found that DWI/MRI was accurate in detecting peritoneal carcinomatosis with $91 \%$ sensitivity, 91\% specificity, 89\% PPV, 93\% NPV, and 91\% accuracy. The size of peritoneal carcinomatosis in their study was smaller than $1 \mathrm{~cm}$ in $36 \%$ and larger than 1 $\mathrm{cm}$ in $29 \%$ and $35 \%$ showed confluent disease. Higher sensitivity in this study may be attributed to a greater percentage of cases with confluent peritoneal disease and may be also attributed to the sensitivity of 3D ADC colored maps.

Other studies also showed the accuracy of DWI in the detection of peritoneal carcinomatosis (qualitative analysis) [25-28]. Yet few studies concerned with quantitative analysis of peritoneal carcinomatosis.

In this study, the mean 3D ADC value of peritoneal carcinomatosis at $b$ value 800 was $0.956 \pm 0.25 \times 10^{-3}$ $\mathrm{mm}^{2} / \mathrm{s}$. Onur et al. [29], in their study which included 28 oncology patients six of them had ovarian cancer, found that the mean ADC value at $b$ value 1000 was $1.09 \pm 0.4\left(\times 10^{-3} \mathrm{~mm}^{2} / \mathrm{s}\right)$. A lower mean $\mathrm{ADC}$ value for peritoneal carcinomatosis in this study may be attributed to low ADC value peritoneal deposits as in cases of metastatic leiomyosarcoma and peritoneal mesothelioma.

In this study, the mean $\mathrm{ADC}$ value of both peritoneal carcinomatosis and malignant lymphadenopathy is 
slightly lower than that of ovarian cancer. In certain cases as cases of tubo-ovarian abscesses, necrotizing caseating granuloma, and ovarian infarction especially in elderly patients, ovarian lesions were mimic of that ovarian cancer as they had low ADC values, associated with peritoneal nodules, and enlarged lymphadenopathy, especially in first two cases so proper history and clinical data are very important for proper diagnosis and management.

In this study, the 3D ADC map was helping in proper assessment of ovarian masses, peritoneal, and nodal deposits. Few studies were done to evaluate the role of 3D ADC maps in discrimination of different tumor histological grading and other studies compared the role of 3D and 2D ADC maps.

Moryia and colleagues [30] used 3D ADC histogram in the differentiation of different histological types of hepatocellular carcinomas and they found that the minimum ADC was the most promising parameter for distinguishing poorly differentiated HCC from the other histological grades.

Tamada et al. [31], in their study which compared the reproducibility and diagnostic performance of $2 \mathrm{D}$ and 3D ROIs for prostatic ADC measurements, found that the use of 3D ROI did not improve the intrareader or inter-reader reproducibility or the diagnostic performance compared with the use of 2D ROI.

This was in contrary to the study done by Lui and colleagues [32] comparing the whole tumor $3 \mathrm{D}$ and $2 \mathrm{D}$ center-slice analysis in both ADC maps of b800 and b1000 and they suggested that the whole tumor 3D analysis of ADC maps provide reliable results and a more comprehensive evaluation of tumor histological grade.

Another study was done by Souza and colleagues [33] in which they compared mean ADC values calculated in 2D and 3D for differentiating healthy brain tissues, glioblastoma, and meningioma and they found that 2D and 3D ADC maps could possibly differentiate meningiomas and glioblastomas or glioblastomas from normal tissues. However, meningiomas and normal tissues can be confused in the 3D analysis because of different cellularity and cellular type variability.

This study had several limitations such as the unequal distribution of ovarian pathologies included in the study and the limited number of cases with primary ovarian malignancy. Our study depended on 3D ADC maps and 2D maps were not included. Furthermore, a limitation related to the cost, availability, and the contraindication of MRI examination was encountered.

A future comparative study comparing and evaluating the diagnostic performance of $2 \mathrm{D}$ and $3 \mathrm{D}$ ovarian ADC maps with a larger sample number and better pathological distribution is recommended.

\section{Conclusion}

Adding DWI and recently developed processed 3D ADC maps to the conventional MR images provides quantitative and qualitative analysis of the ovarian masses, lymph nodes, and peritoneal deposits and hence, increasing the sensitivity, specificity, and accuracy of the non-contrast conventional images. Therefore DWI, and recently developed post-processing 3D ADC, may become promising techniques with applications in various areas of ovarian cancer imaging including diagnosis, staging, and treatment planning especially in patients with relative or absolute contraindications to the use of contrast material.

\section{Acknowledgements}

We thank Ahmed S. Abdelrahman (Department of Radiology) for helping in manuscript writing and revision.

\section{Authors' contributions}

RA and HN Suggest and develop the research idea. RF wrote the manuscript. $\mathrm{HN}$ and $\mathrm{Al}$ analyzed and interpreted the patient data. NC and AM reviewed all patients' magnetic resonance images. All authors read and approved the final manuscript.

\section{Funding}

No funds, sponsorship, or financial support to be disclosed

\section{Availability of data and materials}

The datasets used and/or analyzed during the current study are available from the corresponding author on reasonable request.

\section{Ethics approval and consent to participate}

This study was approved by the Research Ethics Committee of the Faculty of Medicine at Ain Shams University in Egypt on 27 May 2018; reference number of approval: FWA 000017585 . All patients included in this study gave written informed consent to participate in this research.

\section{Consent for publication}

All patients included in this research gave written informed consent to publish the data contained within this study.

\section{Competing interests}

The authors declare that they have no competing interest.

\section{Author details}

${ }^{1}$ Radiology Department, Faculty of Medicine, Ain Shams University, Cairo, Egypt. ${ }^{2}$ Obstetrics and Gynecology Department, Faculty of Medicine, Ain Shams University, Cairo, Egypt.

Received: 26 March 2020 Accepted: 27 May 2020

Published online: 11 June 2020

\section{References}

1. Torre LA, Trabert B, DeSantis CE et al (2018) Ovarian cancer statistics, 2018. CA Cancer J Clin 68:284-296. https://doi.org/10.3322/caac.21456

2. Javadi S, Ganeshan DM, Qayyum A et al (2016) Ovarian cancer, the revised FIGO staging system, and the role of imaging. Am J Roentgenol 206(6): 1351-1360 https://doi.org/10.2214/AJR.15.15199

3. Kiyokawa T, Iwamoto M (2018) Current concept of precancerous and early stage of serous ovarian carcinoma. In: Moriya T (ed) Pathology of Female Cancers. Springer, Singapore https://doi.org/10.1007/978-981-10-8606-9_4

4. Prado AG, Hernando CG, Delgado DV et al (2019) Diffusion-weighted magnetic resonance imaging in peritoneal carcinomatosis from suspected ovarian cancer: diagnostic performance in correlation with surgical findings. Eur J Radiol 121:108696 ISSN 0720-048X. https://doi. org/10.1016/j.ejrad.2019.108696 
5. Kehr E, Soong TR, Hirsch MS (2018) Chapter 28 - Metastatic tumours involving the ovary. In: Crum CP, Nucci MR, Howitt BE, Granter SR, Parast MM, Boyd TK (eds) Diagnostic Gynecologic and Obstetric Pathology (Third Edition), pp 1050-1069 ISBN 9780323447324. https://doi.org/10.1016/B9780-323-44732-4.00028-5

6. Pu T, Xiong L, Liu Q et al (2017) Delineation of retroperitoneal metastatic lymph nodes in ovarian cancer with near-infrared fluorescence imaging. Oncol Lett 14:2869-2877 https://doi.org/10.3892/ol.2017.6521

7. Kang SK, Reinhold C, Atri M et al (2018) ACR Appropriateness Criteria ${ }^{\circledR}$ staging and follow-up of ovarian cancer, expert panel on women's imaging. J Am Coll Radiol 15(5):S198-S207 https://doi.org/10.1016/j.jacr.2018.03.015

8. Schmidt S, Meuli RA, Achtari $C$ et al (2015) Peritoneal carcinomatosis in primary ovarian cancer staging: comparison between MDCT, MRI, and 18FFDG PET/CT. Clin Nucl Med 40(5):371-377 https://doi.org/10.1097/RLU. 0000000000000768

9. Gómez AML, Santana PC, Mourão AP (2020) Dosimetry study in head and neck of anthropomorphic phantoms in computed tomography scans. Sci Med J 2(1):38-43 https://doi.org/10.28991/SciMedJ-2020-0201-6

10. Yavari K (2018) Anti-angiogenesis therapy of cancer cells using $153 \mathrm{Sm}$ Bevasesomab. Emerg Sci J 2(3):130-139

11. Bonekamp S, Corona-Villalobos CP, Kamel IR (2012) Oncologic applications of diffusion weighted MRI in the body. J Magn Reson Imaging 35:257-279 https://doi.org/10.1002/jmri.22786

12. Kim S, Loevner L, Quon H et al (2009) Diffusion-weighted magnetic resonance imaging for predicting and detecting early response to chemoradiation therapy of squamous cell carcinomas of the head and neck. Clin Cancer Res 15(3):986-989 https://doi.org/10.1158/1078-0432. CCR-08-1287

13. Amodeo S, Rosman AS, Desiato $V$ et al (2018) MRI-based apparent diffusion coefficient for predicting pathologic response of rectal cancer after neoadjuvant therapy: systematic review and meta-analysis. Am J Roentgenol 211(6):W 205-W 216

14. Michielsen K, Vergote I, Op de Beeck K et al (2014) Whole-body MRI with diffusion-weighted sequence for staging of patients with suspected ovarian cancer: a clinical feasibility study in comparison to CT and FDG-PET/CT. Eur Radiol 24:889-901 https://doi.org/10.1007/s00330-013-3083-8

15. Baboli M, Zhang J, Kim SG (2019) Advances in diffusion and perfusion MRI for quantitative cancer imaging. Curr Pathobiol Rep 7:129-141 https://doi. org/10.1007/s40139-019-00204-7

16. Ferlay J, Parkin DM, Steliarova-Foucher E (2010) Estimates of cancer incidence and mortality in Europe in 2008. Eur J Cancer 46:765-781 https:// doi.org/10.1016/j.ejca.2009.12.014

17. Prat J, FIGO Committee on Gynecologic Oncology (2015) FIGO's staging classification for cancer of the ovary, fallopian tube, and peritoneum: abridged republication. J Gynecol Oncol 26(2):87-89 https://doi.org/10. 3802/jgo.2015.26.2.87

18. Takeuchi M, Matsuzaki K, Nishitani H et al (2010) Diffusion-weighted magnetic resonance imaging of ovarian tumours: differentiation of benign and malignant solid components of ovarian masses. J Comput Assist Tomogr 34:173e6 https://doi.org/10.1097/RCT.0b013e3181c2f0a2

19. Li W, Chu C, Cui Y, et al. (2012) Diffusion-weighted MRl: a useful technique to discriminate benign versus malignant ovarian surface epithelial tumours with solid and cystic components. Abdom Radiol 37, 897-903. https://doi. org/10.1007/s00261-011-9814-x

20. El Ameen NF, Eissawy MG, Mohsen LAMS et al (2020) MR diffusion versus MR perfusion in patients with ovarian tumours; how far could we get? Egypt J Radiol Nucl Med 51:35 https://doi.org/10.1186/s43055-020-0141-5

21. Klerkx WM, Mali WM, Heintz AP et al (2011) Observer variation of magnetic resonance imaging and diffusion-weighted imaging in pelvic lymph node detection. Eur J Radiol 78(1):71-74. https://doi.org/10.1016/j.ejrad.2009.04.027

22. Li HM, Qiang JW, Xia GL et al (2015) MRI for differentiating ovarian endometrioid adenocarcinoma from high-grade serous adenocarcinoma. J Ovarian Res 8:26 https://doi.org/10.1186/s13048-015-0154-2

23. Oh JW, Rha SE, Oh SN et al (2015) Diffusion-weighted MRI of epithelia ovarian cancers: correlation of apparent diffusion coefficient values with histologic grade and surgical stage. Eur J Radiol 84(4):590-595 https://doi. org/10.1016/j.ejrad.2015.01.005

24. Wang F, Wang Y, Zhou Y et al (2017) Comparison between types I and II epithelial ovarian cancer using histogram analysis of monoexponential, biexponential, and stretched-exponential diffusion models. J Magn Reson Imaging 46:1797-1809. https://doi.org/10.1002/jmri.25722
25. Michielsen K, Dresen R, Vanslembrouck R et al (2017) Diagnostic value of whole-body diffusion-weighted MRI compared to computed tomography for pre-operative assessment of patients suspected for ovarian cancer. Eur J Cancer 83:88-98 https://doi.org/10.1016/j.ejca.2017.06.010

26. Vergote I, Van Gorp T, Amant F et al (2008) Timing of debulking surgery in advanced ovarian cancer. Int J Gynecol Cancer 18(Suppl 1):11-19. https:// doi.org/10.1111/j.1525-1438.2007.01098.x

27. Espada M, Garcia-Flores JR, Jimenez M et al (2013) Diffusion-weighted magnetic resonance imaging evaluation of intraabdominal sites of implants to predict likelihood of suboptimal cytoreductive surgery in patients with ovarian carcinoma. Eur Radiol 23:2636-2642 https://doi.org/10.1007/s00330013-2837-7

28. Low RN, Sebrechts CP, Barone RM et al (2009) Diffusion weighted MRI of peritoneal tumours: comparison with conventional MRI and surgical and histopathologic findings-a feasibility study. Am J Roentgenol 193(2):461470. https://doi.org/10.2214/AJR.08.1753

29. Onur MR, Akyol M, Poyraz AK et al (2012) Diagnosis of peritoneal metastases with abdominal malignancies: role of ADC measurement on diffusion weighted MRI. Eurasian J Med 44(3):163-168 https://doi.org/10. 5152/eajm.2012.38

30. Moriya T, Saito K, Tajima $Y$ et al (2017) 3D analysis of apparent diffusion coefficient histograms in hepatocellular carcinoma: correlation with histological grade. Cancer Imaging 17:1 https://doi.org/10.1186/ s40644-016-0103

31. Tamada T, Huang C, Ream JM et al (2018) Apparent diffusion coefficient values of prostate cancer: comparison of 2D and 3D ROls. Am J Roentgenol 210(1):113-117 https://doi.org/10.2214/AJR.17.18495

32. Liu Y, Zhang Y, Cheng R et al (2019) Radiomics analysis of apparent diffusion coefficient in cervical cancer: a preliminary study on histological grade evaluation. J Magn Reson Imaging 49:280-290. https://doi.org/10. 1002/jmri.26192

33. Souza M, Castellano G, Baldissin MM et al (2012) Comparison of ADC values obtained in 2D and 3D for differentiation between healthy brain tissues, glioblastoma and meningioma. World Congress on Medical Physics and Biomedical Engineering May 26-31, 2012, Beijing, pp 975-978 https://doi. org/10.1007/978-3-642-29305-4_256

\section{Publisher's Note}

Springer Nature remains neutral with regard to jurisdictional claims in published maps and institutional affiliations.

\section{Submit your manuscript to a SpringerOpen ${ }^{\circ}$ journal and benefit from:}

- Convenient online submission

- Rigorous peer review

- Open access: articles freely available online

High visibility within the field

- Retaining the copyright to your article

Submit your next manuscript at $>$ springeropen.com 